\title{
Nurse-led multidisciplinary programme for patients with COPD in primary health care: a controlled trial
}

\author{
Ann-Britt Zakrisson ${ }^{a, b, c}$, Peter Engfeldt ${ }^{a, b}$, Doris Hägglund ${ }^{b}$, Sigrid Odencrants $^{b}$, \\ Mikael Hasselgren $^{\text {adde, }}$, Mats Arne ${ }^{\mathrm{d}, \mathrm{e}}$, Kersti Theander ${ }^{\text {,ff }}$ \\ a Family Medicine Research Centre, Örebro University, Sweden \\ ${ }^{\mathrm{b}}$ School of Health and Medical Sciences, Örebro University, Sweden \\ c Centre for Assessment of Medical Technology in Örebro, Sweden \\ ${ }^{d}$ Department of Public Health and Caring Sciences, Family Medicine and Clinical Epidemiology, Uppsala University, Sweden \\ e Primary Care Research Unit, County Council in Värmland, Karlstad, Sweden \\ Department of Nursing, Karlstad University, Sweden
}

Originally submitted 6th May 2010; resubmitted 11th August 2010; revised 27th October 2010; further revision 20th January 2011; accepted 4th April 2011; online 17th June 2011

\begin{abstract}
Aim: To investigate the effects of a nurse-led multidisciplinary programme (NMP) of pulmonary rehabilitation in primary health care with regard to functional capacity, quality of life (QoL), and exacerbations among patients with chronic obstructive pulmonary disease (COPD). Method: A 1-year longitudinal study with a quasi-experimental design was undertaken in patients with COPD, 49 in the intervention group and 54 in the control group. Functional capacity was assessed using the 6-minute walking test, and quality of life (QoL) was assessed using the Clinical COPD Questionnaire. Exacerbations were calculated by examination of patient records.

Results: No significant differences were found between the groups in functional capacity and QoL after 1 year. The exacerbations decreased in the intervention group $(n=-0.2)$ and increased in the control group $(n=0.3)$ during the year after NMP. The mean difference of change in exacerbation frequency between the groups was statistically significant after one year $(p=0.009)$.

Conclusions: The NMP in primary care produced a significant reduction in exacerbation frequency, but functional capacity and QoL were unchanged. More and larger studies are needed to evaluate potential benefits in functional capacity and QoL.

(C) 2011 Primary Care Respiratory Society UK. All rights reserved.

A-B Zakrisson et al. Prim Care Respir J 2011; 20(4): 427-433

http://dx.doi.org/10.4104/pcrj.2011.00060
\end{abstract}

Keywords COPD, management, exacerbations, nurse, primary care, rehabilitation, pulmonary, quantitative

See linked editorial by George and Fletcher on pg 355

\section{Introduction}

Chronic obstructive pulmonary disease (COPD) is a systemic inflammatory disease with an increased risk of cardiovascular disease and neurological and musculoskeletal symptoms ${ }^{1}$ which affects patients' functioning in daily life. Pulmonary rehabilitation (PR) reduces hospital admissions and mortality from exacerbations compared with usual community care (i.e. no rehabilitation). ${ }^{2}$ PR also increases quality of life (QoL), but the long-term effects are unknown. ${ }^{3}$ PR is recommended in international ${ }^{4}$ and national ${ }^{5,6}$ guidelines

Functional capacity is decreased in patients with COPD compared with other chronic diseases such as diabetes mellitus. ${ }^{8}$ Limited functional capacity results in most patients from exacerbations, dyspnoea, fatigue, and decreased exercise tolerance. ${ }^{4}$ Anxiety, depression, and poor motivation also have an impact on symptom perception leading to impairment of functional capacity. ${ }^{4}$

The term QoL is used to 'signify the gap between desires and achievements that is specifically due to the disease'..$^{9}$ Patients with chronic diseases including COPD have a lower chance of achieving a satisfactory QoL than those without a chronic disease. ${ }^{10,11}$ In patients with COPD factors such as exacerbations, chronic cough, dyspnoea, ${ }^{12}$ and fatigue ${ }^{13}$ determine QoL.

Exacerbations have a negative impact on patient because

\footnotetext{
* Corresponding author: Mrs Ann-Britt Zakrisson, Family Medicine Research Centre, Örebro University, Box 1613, Örebro, 701 16, Sweden Tel: +46706-863959 Fax: +4619-6025797 E-mail: ann-britt.zakrisson@orebroll.se
} 
they impair functional capacity, decrease exercise tolerance and QoL, ${ }^{4,12}$ and have a serious impact on morbidity and mortality. ${ }^{14}$ The frequency of exacerbations accelerates the disease progression..$^{15} \mathrm{~A}$ patient with COPD has 2.5-3 exacerbations per year on average ${ }^{16}$ and recovery takes a long time (up to three months). ${ }^{17}$

PR can be valuable for all patients with respiratory symptoms that are associated with limited functional capacity or reduced QoL. ${ }^{4}$ Swedish national guidelines ${ }^{5}$ recommend PR in patients with COPD in GOLD stages 2 and $3 .{ }^{18}$

PR focuses on physical exercise but includes patient education for self-management and lifestyle changes, energy saving techniques, psychosocial intervention, and dietary intervention. ${ }^{4}$ In the hospital setting, PR has been shown to increase functional capacity and QoL. ${ }^{3}$ To our knowledge, only one study with a multidisciplinary arrangement has been performed in the PHC setting. ${ }^{19}$ The intervention consisted of an integrated disease management programme including physical activity exercise three times a week over a period of three months and teaching of self-management. The patients' QoL increased and dyspnoea decreased one year after the programme. ${ }^{19} \mathrm{~A}$ study of patient education in PHC showed that usual care with only pharmacological treatment did not have an effect on the QoL and smoking habits of the patients. ${ }^{20}$ The results were in accordance with other studies. ${ }^{3}$

In Sweden about 50\% of the PHC centres have a nurse-led asthma/COPD clinic $^{21}$ that routinely performs spirometry for diagnoses and gives patient education. PR or a multidisciplinary programme is unusual in the PHCs, and structured programmes for COPD need to be established in primary care..22 The aim of this study, conducted in the middle of Sweden, was to investigate the effects of a nurse-led multidisciplinary programme (NMP) - incorporating pulmonary rehabilitation - in a primary health care (PHC) setting, on functional capacity, QoL and exacerbations in patients with COPD.

\section{Methods}

This was a 1-year longitudinal study with a quasi-experimental design. The patients in the intervention group were assessed at baseline and after 2 months, 5 months, and 1 year. Patients in the control group were assessed at baseline and after 1 year. The intervention was a 6-week NMP. The primary outcomes were functional capacity, QoL, and exacerbation frequency.

\section{Participants}

The inclusion criteria were: COPD diagnosed for at least 1 year with forced expiratory volume in 1 s/forced vital capacity $\left(\mathrm{FEV}_{1} / \mathrm{FVC}\right.$ ) ratio $<70$ and $\mathrm{FEV}_{1} 40-59 \%$ of predicted, representing GOLD stages 2 and $3 ;^{18}$ age 60-75 years; ability to understand and be able to express themselves in the Swedish language; and pulmonary function tests performed during the year before inclusion. The exclusion criteria were: cognitive impairment, substance abuse, severe psychological disease, malignancy, or participation in any other study.

\section{Recruitment}

PHC centres with an asthma/COPD clinic in two county councils (numbering 21 and eight, respectively) in central Sweden were invited to participate. Nine PHC centres (six and three, respectively) consented to participate in the study, and their patients constituted the intervention group. The participating PHC centres were located in both urban and rural areas and the patients in their catchment area were living in the immediate surroundings. The remaining $\mathrm{PHC}$ centres $(n=15)$ in one of the county councils were invited to participate as control centres and their patients constituted the control group (Figure 1). These patients received usual care (i.e. no teamwork, no structured programme, only individual consultations). Our intention was to randomise the $\mathrm{PHC}$ centres to the intervention or control group, but this was not possible because of difficulties in establishing a multidisciplinary team in the PHC centres.

\section{a) Recruitment - intervention group}

Each asthma/COPD nurse searched in the patient administrative system to identify patients with diagnoses of COPD, emphysema, and chronic bronchitis. A total of 1,042 patients were assessed for eligibility. Of these, 959 were excluded because they did not meet the inclusion criteria. Each PHC centre had 5-13 patients with COPD according to the inclusion criteria and these patients were invited to participate. A total of 49 patients ( 25 men and 24 women) were included in the intervention group. Eight patients missed 1-2 sessions of the NMP. QoL was analysed in 44 patients and six could not manage the 6-minute walking test (6MWT) at 1-year follow-up. Participant flow and reasons for missing assessments are shown in Figure 1.

\section{b) Recruitment - control group}

The group consisted of patients from the remaining $15 \mathrm{PHC}$ centres in one county council, and the first author performed the search for patients. In the control group, 786 patients were assessed for eligibility and 693 were excluded because they did not meet the inclusion criteria. A total of 54 patients (32 men and 22 women) were included. At the 1-year follow-up, 45 patients were analysed for QoL and three could not manage the 6MWT. Participant flow and reasons for missing assessments are shown in Figure 1.

\section{The intervention}

The NMP was conducted with the existing resources in each of the nine PHC centres. The intervention consisted of NMP during 2007 and 2008. The NMP consisted of 2 hrs (1 hr theory and 1 hr physical activity) every week for six weeks. The educational material in the NMP was based on international ${ }^{4}$ and national ${ }^{5,6}$ guidelines. The asthma/COPD nurse and the physician held one session of education about the disease and medication, anatomy, and physiology. Nutrition advice on the importance of adequate nutrition and discussions related to undernourishment 
Figure 1. Number of included and excluded patients and the reasons for dropouts

Participant flow, intervention group

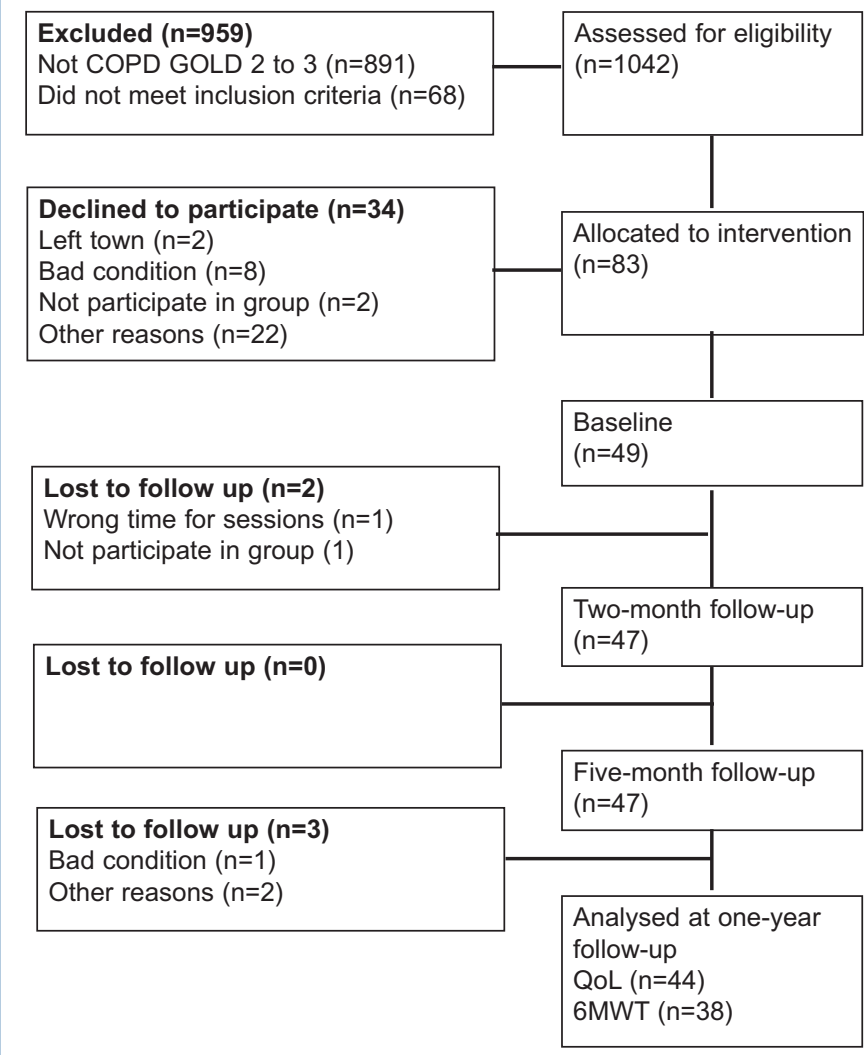

and overweight were held by the asthma/COPD nurse. One session on anxiety and stress management was held by a social worker, and a session on working speed and simpler working techniques was held by an occupational therapist. The physiotherapist provided education on physical activity in one theory session and conducted the physical activity sessions, which included muscle strengthening, breathing and coughing techniques, and relaxation techniques. The theory sessions continued each week with $1 \mathrm{hr}$ of practice in physical activity exercise each week and an individual home training programme was given to each patient. The next of kin received concise information on all topics of the NMP at one session. Advice to give up smoking was given throughout the whole programme. To standardise the NMP, all team members received one day of training in COPD and the study design before the start of the study. The asthma/COPD nurse also received a half-day of training in assessments and nutrition advice.

\section{Data collection}

Assessments in the intervention group were performed separately from the 6-week NMP at baseline, after 2 months, 5 months, and 1 year. Functional capacity was measured with a $6 \mathrm{MWT}$ in which the patient is asked to walk along a measured line and the distance covered is measured after 6 mins. ${ }^{23} \mathrm{QoL}$
Participant flow, control group

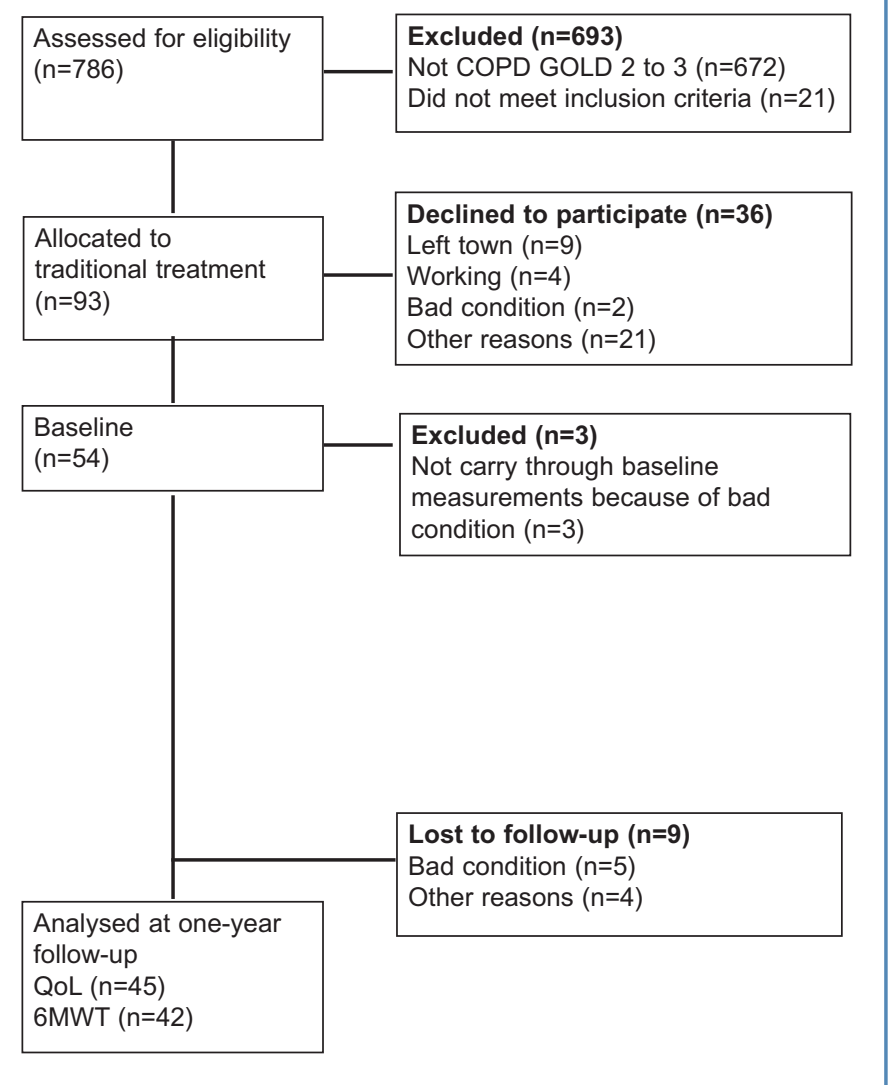

was measured using the Clinical COPD Questionnaire (CCQ), a disease-specific questionnaire consisting of 10 questions on a seven-point scale from 0 (asymptomatic/no limitations) to 6 (extremely symptomatic/totally limited). ${ }^{24}$ The total score is calculated by adding the scores of the 10 items, divided by $10 .{ }^{24}$ The CCQ examines QoL in three dimensions: symptoms (4 items), functional state (4 items), and mental state ( 2 items). The instrument of CCQ is validity and reliability tested for Swedish conditions with a Cronbach's alpha score of $0.84 .^{25}$

The number of exacerbations, smoking status, and drugs prescribed for COPD (i.e. inhaled corticosteroids, short-acting and long-acting $\beta_{2}$-agonists, combination therapy, tiotropium bromide, and ipratropium) from 1 year before the intervention to 1 year after were assessed from the patient records. An exacerbation was defined as occurring when a patient had emergency treatment with nebulisation, peroral corticosteroids or antibiotics, or admission to hospital, according to national guidelines. ${ }^{26}$ Body mass index (BMI) was calculated as weight $(\mathrm{kg}) /$ length $^{2}(\mathrm{~m}) .{ }^{27}$ Pulmonary function (FEV $/$ FVC and FEV 1 ) was measured using routine spirometry. ${ }^{28}$ All assessments were conducted at each PHC centre.

A nurse in the PHC who was not involved in the study performed the assessment at baseline and after 1 year in the 
control group. The first author performed the examination of the patient records for the control group.

A pilot study was performed in one PHC centre in 2004. The results from the pilot study were used to calculate the sample size and were not included in this study.

\section{Data analysis}

For analysis of the parametric variables age, $\mathrm{FEV}_{1}, \mathrm{BMI}$, 6MWT, and exacerbation frequency, comparisons between and within the groups were performed using independent $t$ tests and paired sample $t$ tests. The mean differences in the change from baseline to the 1-year follow-up in 6MWT and exacerbation frequency between the groups were tested using the $t$ test for independent groups. For ordinal scale, variables such as CCQ, comparisons between and within the groups were calculated using the Mann-Whitney $U$ test and Wilcoxon signed ranks test. Statistical analysis was performed using SPSS 16.0.

Before the study no data concerning QoL in PHC were available to calculate the study sample size. Results from the pilot study were used and from the data it was assumed that about $75 \%$ of the patients in the intervention group and $20 \%$ of the patients in the control group should improve their QoL. In the present study the number of patients needed with a power of $80 \%$ and with a significance level of 0.05 was then calculated to be about 20 patients in each group. To compensate for dropouts we planned to include 50 patients in each group, giving a total of 100 patients. ${ }^{29}$

\section{Ethical considerations}

The Research Ethics Committee in Uppsala, Sweden approved the study (Dnr 2006/322). The patients in both groups were invited to participate with an information letter that included informed consent.

\begin{tabular}{|c|c|c|c|c|c|}
\hline & \multicolumn{2}{|c|}{$\begin{array}{l}\text { Intervention } \\
(\mathrm{n}=49)\end{array}$} & \multicolumn{2}{|c|}{$\begin{array}{l}\text { Control } \\
(n=54)\end{array}$} & \multirow[b]{2}{*}{$\begin{array}{l}\mathrm{p} \\
\text { value }\end{array}$} \\
\hline & $\mathrm{n}$ & $\begin{array}{l}\text { Mean } \\
\text { (SD) }\end{array}$ & $n$ & $\begin{array}{l}\text { Mean } \\
\text { (SD) }\end{array}$ & \\
\hline Male/Female & $25 / 24$ & & 321 & & \\
\hline Smokers & 16 & & 23 & & 0.299 \\
\hline Age & & $67(4)$ & & $68(5)$ & 0.373 \\
\hline $\mathrm{FEV}_{1}, \%$ pred. & & $49(8)$ & & $49(8)$ & 0.966 \\
\hline BMI & & $28(6)$ & & $27(6)$ & 0.576 \\
\hline 6MWT (m) & & $391(89)$ & & $360(88)$ & 0.114 \\
\hline$C C Q, 0-6$ & & $2(1)$ & & $2(1)$ & 0.651 \\
\hline Exacerbations (n) & & $0.8(1.2)$ & & $0.4(1.1)$ & 0.146 \\
\hline
\end{tabular}

\section{Results}

There were no significant differences between the intervention and control groups at baseline with regard to number of smokers, age, $\mathrm{FEV}_{1}, \mathrm{BMI}, 6 \mathrm{MWT}, \mathrm{CCQ}$, and exacerbation frequency (Table 1). No significant differences were found between the groups in 6MWT and CCQ at the 1year follow-up. The exacerbation frequency decreased by 0.24 in the intervention group and increased by 0.26 exacerbations in the control group. The mean difference in the change between the groups in exacerbation frequency was statistically significant $(p=0.009)$ during the 1 -year study (Table 2).

In both the intervention and control groups the 6MWT improved significantly after 1 year $(22 \mathrm{~m}$ and $38 \mathrm{~m}$, respectively, $\mathrm{p}<0.005$, Table 3).

\section{Table 2. Mean values for 6MWT, exacerbations, and CCQ at baseline and after 1 year for intervention and control} groups and comparison of mean difference of changes between the groups in 6MWT and exacerbations

\begin{tabular}{|c|c|c|c|c|c|c|}
\hline & \multicolumn{2}{|c|}{ Intervention $(n=44)$} & \multicolumn{4}{|c|}{ Control $(n=45)$} \\
\hline & \multirow{2}{*}{$\begin{array}{l}\text { Baseline } \\
\text { Mean (SD) }\end{array}$} & \multirow{2}{*}{$\begin{array}{l}1 \text { year } \\
\text { Mean diff (SD) }\end{array}$} & \multirow{2}{*}{$\begin{array}{l}\text { Baseline } \\
\text { Mean (SD) }\end{array}$} & \multirow{2}{*}{$\begin{array}{l}1 \text { year } \\
\text { Mean diff (SD) }\end{array}$} & \multicolumn{2}{|c|}{ Mean diff of change } \\
\hline & & & & & $95 \% \mathrm{Cl}$ & $\mathrm{p}$ value \\
\hline Exacerbations (n) & $0.8(1.2)$ & $-0.2(0.9)$ & $0.4(1.1)$ & $0.3(0.9)$ & -0.9 to -0.1 & 0.009 \\
\hline CCQ, 0-6 & $2.0(1.0)$ & $2.0(0.9)$ & $2.0(1.0)$ & $2.0(0.8)$ & & 0.866 \\
\hline
\end{tabular}

Table 3. Changes in the 6-minute walking test 1 year from baseline in the intervention and control groups

\begin{tabular}{llllllllll} 
& \multicolumn{3}{l}{ Baseline } & \multicolumn{2}{c}{2 months } & \multicolumn{2}{c}{5 months } & \multicolumn{2}{c}{1 year follow-up } \\
& Mean & (SD) & Diff & $p$ value & Diff & $p$ value & Diff & $95 \%$ Cl & $p$ value \\
\hline Intervention $(n=38)$ & 388 & 94 & 30 & $<0.001$ & 25 & 0.005 & 22 & -8 to -39 & 0.004 \\
\hline Control $(n=42)$ & 360 & 88 & & & & & 38 & -15 to -62 & 0.002 \\
\hline
\end{tabular}




\begin{tabular}{|c|c|c|c|c|c|c|c|c|}
\hline \multirow[b]{2}{*}{ Variable } & \multicolumn{2}{|c|}{ Baseline } & \multicolumn{2}{|c|}{2 months } & \multicolumn{2}{|c|}{5 months } & \multicolumn{2}{|c|}{1 year follow-up } \\
\hline & Mean & (SD) & Diff & $\mathrm{p}$ value & Diff & $\mathrm{p}$ value & Diff & $\mathrm{p}$ value \\
\hline CCQ Total, 0-6 & 2 & (1) & -0.5 & $<0.001$ & -0.3 & 0.007 & -0.3 & 0.022 \\
\hline Symptom, 0-6 & 2 & (1) & -0.4 & 0.009 & -0.3 & 0.054 & -0.2 & 0.044 \\
\hline Functional state, 0-6 & 2 & (1) & -0.5 & $<0.001$ & -0.3 & 0.029 & -0.3 & 0.095 \\
\hline Mental state, 0-6 & 2 & (1) & -0.5 & 0.015 & -0.2 & 0.471 & -0.2 & 0.366 \\
\hline
\end{tabular}

Table 5. Changes in the Clinical COPD Questionnaire

(CCQ) in the control group during the 1-year study

period $(n=45)$

\begin{tabular}{lllll} 
& \multicolumn{2}{l}{ Baseline } & \multicolumn{2}{c}{ 1 year follow-up } \\
Variable & \multicolumn{2}{c}{ Mean (SD) } & Diff & p value \\
\hline CCQ Total, 0-6 & 2 & $(1)$ & -0.3 & 0.086 \\
\hline Symptom, 0-6 & 2 & $(1)$ & -0.1 & 0.654 \\
\hline Functional state, 0-6 & 2 & $(1)$ & -0.3 & 0.150 \\
\hline Mental state, 0-6 & 2 & $(1)$ & -0.3 & 0.207 \\
\hline
\end{tabular}

In the intervention group the total QoL was significantly improved compared with baseline after 2 months $(p<0.001)$, 5 months $(p=0.007)$, and 1 year $(p=0.022$, Table 4$)$. There were no significant improvements in QoL at the 1-year followup in the control group (Table 5).

More drugs were prescribed for COPD (i.e. not increase in dosage) during the 1-year study for $11 \%$ of patients in the intervention group and for $22 \%$ of patients in the control group. During the study four of 16 patients stopped smoking in the intervention group and seven of 23 in the control group.

\section{Discussion}

The main results of this longitudinal study are that there were no statistical differences in functional capacity and QoL between the intervention and control groups after 1 year. Functional capacity increased significantly from baseline to the 1-year follow-up in both the intervention and control groups. However, the patients in the intervention group increased their QoL significantly after 1 year. The exacerbation frequency decreased in the intervention group and increased in the control group; this difference was statistically significant.

The 6MWT was increased in both groups of participants but did not reach the reported mean 6MWT distance of $613 \mathrm{~m}$ in healthy elderly people. ${ }^{30}$ The 6MWT is a useful method for evaluating the effect of treatment on a patient's daily activity tolerance. ${ }^{31}$ During the study period the 6MWT also increased in patients in the control group. It is possible that the measurements performed for the baseline data had influenced the patients to consider starting regular physical activity, since it is routine for nurses at a nurse-led asthma/COPD clinic to give information concerning physical activity, ${ }^{21}$ despite the fact that the same nurse performed the baseline data for all patients in the control group and was instructed not to give any advice to patients concerning physical activity or other treatments.

This study showed that six weeks of NMP had positive effects on functional capacity and QoL for up to 1 year in the intervention group. In studies performed in hospital settings, positive effects on these parameters have mostly been shown for up to 6 months. ${ }^{3}$ However, the study by Chavannes et al. ${ }^{19}$ also conducted in primary care, showed similar longitudinal effects on QoL as in the present study. One reason for the positive results for QoL could be that the PHC centres had to build up COPD teams, which necessitated educating the staff on how to manage patients with COPD. ${ }^{3,4}$ A comprehensive approach to a chronic care model also probably improves COPD outcomes. ${ }^{32}$ In the present study QoL was measured using the CCQ in three domains: symptoms, functional state, and mental state. ${ }^{24}$ After two months all three domains were increased. The minimal clinically important difference (MCID) for the CCQ has shown an average change in score of 0.5 for the total score. ${ }^{24,25}$ The MCID in the present study was reached after two months in the intervention group but did not persist during the year. In the control group no MCID was achieved. The results indicate that even a small contribution such as a 6-week NMP in PHC could have positive effects on patients with COPD.

The study shows that more drugs were prescribed in the control group but there was no increase in QoL. However, it has been shown that usual care with only pharmacological treatment does not have an effect on QoL. ${ }^{20}$ It is possible that some effects on 6MWT could depend on the pharmacological treatment.

In this study the frequency of exacerbations decreased in the intervention group and increased in the control group, which indicates that NMP over six weeks may lead to a reduction in exacerbations. However, it is also possible that the results could be due to regression to the mean. The findings are in accordance with the results reported by a Cochrane review, where the included studies had PR for six months. ${ }^{2}$ Another Cochrane 
review reported that self-management education reduced hospital admissions for exacerbations. ${ }^{33}$ Thus, NMP may enable patients to perform daily activities, since exacerbations are devastating for the patient as they impair functional performance with decreased exercise tolerance and QoL., 412

Most of the patients in the present study were obese or overweight, a finding also seen in another study. ${ }^{34}$ The patients examined and treated in hospital settings are often underweight, indicating more serious COPD. ${ }^{3,35}$ It will be a challenge for primary care to deal with the problem of obesity. Specific interventions addressing obesity include nutritional education, restricted calorie meal planning, encouragement for weight loss and psychological support, ${ }^{4}$ resources not currently available in primary care. ${ }^{22}$

One of the inclusion criteria in this study was the GOLD stage of the disease ${ }^{18}$ which was obtained by spirometric examination (i.e. a physical investigation that is not related to the patient's functional capacity and QoL). The patient's functional capacity measured using 6MWT varied to a great extent in different patients. The QoL also varied in both groups, but was generally fairly good at baseline and therefore had little scope to show large improvements. Nevertheless, QoL showed a statistically significant increase in the intervention group, but there was no difference between the groups at 1-year follow-up. A study by Izquierdo et al. ${ }^{36}$ showed that patients with COPD in PHC had a lower disease burden than those in specialist clinics. This may mean that not all of the patients in the current study were in need of NMP. Inclusion of patients should perhaps be based on the International Classification of Functioning (ICF) ${ }^{37}$ or BODE index, ${ }^{38}$ both of which indicate the patient's function in daily life.

The reliability of the intervention group could have been influenced by the fact that nine nurses made assessments of the patients in the group, even though the teams all had the same training before the start of the study to standardise the assessments and the NMP. The reliability was stronger in the control group since only one nurse made all the assessments in all patients, both at baseline and at the 1-year follow up. Patient education was also given by different professionals in the nine PHC centres. Patient education is related to the personality, creativity, and experience of the professionals ${ }^{39,40}$ which could have influenced reliability.

One limitation of the present study was the power calculation. The power of the results for QoL was found to be very low at $25 \%$. This was because there were no data on the effects of NMP in PHC so the data had to be taken from the pilot study. Because of the low power of this study, the results should be interpreted with caution.

\section{Conclusions}

The present study shows that even a small contribution such as six weeks of NMP seems to reduce the COPD exacerbation frequency. There were no significant differences in functional

\section{Summary box}

Difficulties encountered during this study

Difficulties in building teams in PHC made it difficult to realise this study with enough power.

Alternative methodologies that would have been helpful in answering the research question

A randomised controlled trial would have been the most appropriate design to assure the results.

New questions arising from the study

Is the classification of COPD by spirometry an adequate method to select patients? How can we help and treat overweight patients with COPD in PHC?

Lessons for clinical practice

Collaboration in teamwork and a structured approach is a benefit for patients with COPD, even in PHC

after one year. However, functional capacity and QoL increased in the intervention group. The establishment of COPD multidisciplinary teams appears to provide the possibility of a higher quality of care for patients with COPD. However, more studies are needed to evaluate the potential benefits in functional capacity and QoL.

\section{Handling editor}

Onno van Schayck

\section{Statistical review}

Gopal Netuveli

\section{Conflicts of interest}

The authors declare that they have no conflicts of interest in relation to this article.

\section{Contributorship}

We thank all patients and the teams in the primary health care centres for their participation. We also thank statistician Anna-Maria Kling and Anders Magnuson, research administrator Susanne Collgård and RN Ewa Löfgren in Family Medicine Research Centre for their support and advice.

\section{Funding}

The Research Committe of Örebro County Council and the Regional Research Council in the region of Uppsala and Örebro have founded this study.

\section{References}

1. Agusti AG. Systemic effects of chronic obstructive pulmonary disease. Proc Am Thorac Soc 2005;2(4):367-70; discussion 71-2. http://dx.doi.org/ 10.1513/pats.200504-026SR

2. Puhan $M$, Scharplatz $M$, Troosters T, Walters EH, Steurer J. Pulmonary rehabilitation following exacerbations of chronic obstructive pulmonary disease. Cochrane Database Syst Rev 2009;(1):CD005305.

3. Lacasse $Y$, Goldstein R, Lasserson TJ, Martin S. Pulmonary rehabilitation for chronic obstructive pulmonary disease. Cochrane Database Syst Rev 2006;(4):CD003793.

4. Nici L, Donner C, Wouters E, et al. American Thoracic Society/European Respiratory Society statement on pulmonary rehabilitation. Am J Respir Crit Care Med 2006;173(12):1390-413. http://dx.doi.org/10.1164/rccm.200508-1211ST

5. Socialstyrelsen. Socialstyrelsens riktlinjer för vård av astma och kroniskt obstruktiv lungsjukdom (KOL): faktadokument och beslutsstöd för prioriteringar. Stockholm: Socialstyrelsen, 2004 
6. Svensk lungmedicinsk förening. Nationellt vårdprogram för $\mathrm{KOL}$, Kroniskt Obstruktiv Lungsjukdom. 2006. http://www.slmf.se/kol/ (accessed 10 Dec 2009).

7. Leidy NK. Functional status and the forward progress of merry-go-rounds: toward a coherent analytical framework. Nurs Res 1994;43(4):196-202. http://dx.doi.org/ 10.1097/00006199-199407000-00002

8. Arne M, Janson C, Janson S, et al. Physical activity and quality of life in subjects with chronic disease: Chronic obstructive pulmonary disease compared with rheumatoid arthritis and diabetes mellitus. Scand I Prim Health Care 2009; 27(3):141-7.

9. Jones PW. Issues concerning health-related quality of life in COPD. Chest 1995;107(5 Suppl):187S-93S. http://dx.doi.org/10.1378/chest.107.5_Supplement.1875

10. Heyworth IT, Hazell ML, Linehan MF, Frank TL. How do common chronic conditions affect health-related quality of life? Br J Gen Pract 2009;59(568):807-08. http://dx.doi.org/10.3399/bjgp09X453990

11. Wang HM, Beyer M, Gensichen J, Gerlach FM. Health-related quality of life among general practice patients with differing chronic diseases in Germany: cross sectional survey. BMC Public Health 2008;8:246. http://dx.doi.org/10.1186/1471-2458-8246

12. Miravitlles M, Molina J, Naberan $\mathrm{K}$, et al. Factors determining the quality of life of patients with COPD in primary care. Ther Adv Respir Dis 2007;1(2):85-92. http://dx.doi.org/10.1177/1753465807086097

13. Theander $K$, Jakobsson $P$, Jorgensen $N$, Unosson $M$. Effects of pulmonary rehabilitation on fatigue, functional status and health perceptions in patients with chronic obstructive pulmonary disease: a randomized controlled trial. Clin Rehabil 2009;23(2):125-36. http://dx.doi.org/10.1177/0269215508096174

14. Donaldson GC, Seemungal TA, Bhowmik A, Wedzicha JA. Relationship between exacerbation frequency and lung function decline in chronic obstructive pulmonary disease. Thorax 2002;57(10):847-52. http://dx.doi.org/10.1136/thorax.57.10.847

15. Cote CG, Dordelly $\amalg$, Celli BR. Impact of COPD exacerbations on patient-centered outcomes. Chest 2007;131(3):696-704. http://dx.doi.org/10.1378/chest.06-1610

16. Wedzicha JA, Donaldson GC. Exacerbations of chronic obstructive pulmonary disease. Respir Care 2003;48(12):1204-13; discussion 13-5.

17. Seemungal TA, Donaldson GC, Bhowmik A, Jeffries DJ, Wedzicha JA. Time course and recovery of exacerbations in patients with chronic obstructive pulmonary disease. Am J Respir Crit Care Med 2000;161(5):1608-13.

18. GOLD. Executive Summary: Global Strategy for the Diagnosis, Management, and Prevention of COPD. NHLBI/WHO Workshop Report, 2007 http://www.goldcopd.com/Guidelineitem.asp?|1=2\&|2=1\&intld=996 (accessed 25 Sept 2008).

19. Chavannes NH, Grijsen M, van den Akker M, et al. Integrated disease management improves one-year quality of life in primary care COPD patients: a controlled clinical trial. Prim Care Respir J 2009;18(3):171-6. http://dx.doi.org/10.3132/pcrj.2009.00003

20. Efraimsson EO, Hillervik C, Ehrenberg A. Effects of COPD self-care management education at a nurse-led primary health care clinic. Scand J Caring Sci 2008;22(2):178-85. http://dx.doi.org/10.1111/j.1471-6712.2007.00510.x

21. Lisspers K, Stallberg B, Hasselgren M, Johansson G, Svardsudd K. Organisation of asthma care in primary health care in Mid-Sweden. Prim Care Respir J 2005;14(3):147-53. http://dx.doi.org/10.1016/j.pcrj.2005.03.003

22. Thorn J, Norrhall M, Larsson $R$, et al. Management of chronic obstructive pulmonary disease (COPD) in primary care: a questionnaire survey in western
Sweden. Prim Care Respir J 2008;17(1):26-31. http://dx.doi.org/ 10.3132/pcri.2008.00008

23. van Stel HF, Bogaard JM, Rijssenbeek-Nouwens LH, Colland VT. Multivariable assessment of the 6-min walking test in patients with chronic obstructive pulmonary disease. Am J Respir Crit Care Med 2001;163(7):1567-71.

24. Van Der Molen T, Willemse BW, Schokker S, Ten Hacken NH, Postma DS, Juniper EF. Development, validity and responsiveness of the Clinical COPD Questionnaire. Health Qual Life Outcomes 2003;1(1):13. http://dx.doi.org/10.1186/1477-7525-1-13

25. Ställberg B, Nokela M, Ehrs PO, Hjemdal P, Jonsson EW. Validation of the Clinical COPD Questionnaire (CCQ) in primary care. Health Qual Life Outcomes 2009;7:26. http://dx.doi.org/10.1186/1477-7525-7-26

26. Läkemedelsverket. Farmakologisk behandling av kroniskt obstruktiv lungsjukdom KOL. 2009 http://www.lakemedelsverket.se/upload/halso-och-sjukvard/ behandlingsrekommendationer/KOL_bakgrund_webb.pdf (accessed 23 June 2009).

27. World Health Organisation. Physical status: the use of interpretation of anthropometri. Report of a WHO Expert Committee. Report No. 854. Geneva, 1995.

28. Hedenström H. Värt att veta om spirometri. 3. ed. Skärholmen: Boehringer Ingelheim, 2003.

29. Altman D. Practical statistics for medical research. London: Chapman \& Hall, 1999.

30. Du H, Newton PJ, Salamonson Y, Carrieri-Kohlman VL, Davidson PM. A review of the six-minute walk test: its implication as a self-administered assessment tool. Eur J Cardiovasc Nurs 2009;8(1):2-8. http://dx.doi.org/10.1016/j.ejcnurse.2008.07.001

31. Leidy NK. Evolving concepts in the measurement of treatment effects. Proc Am Thorac Soc 2006;3(3):212-17. http://dx.doi.org/10.1513/pats.200512-128SF

32. Braman SS, Lee DW. Primary care management of chronic obstructive pulmonary disease: an integrated goal-directed approach. Curr Opin Pulm Med 2010;16(2):83-8. http://dx.doi.org/10.1097/MCP.0b013e3283354981

33. Effing T, Monninkhof EM, van der Valk PD, et al. Self-management education for patients with chronic obstructive pulmonary disease. Cochrane Database Syst Rev 2007;(4):CD002990.

34. Marquis K, Maltais F, Duguay $V$, et al. The metabolic syndrome in patients with chronic obstructive pulmonary disease. J Cardiopulm Rehabil 2005;25(4):226-32; discussion 33-4. http://dx.doi.org/10.1097/00008483-200507000-00010

35. Griffiths TL, Burr ML, Campbell IA, et al. Results at 1 year of outpatient multidisciplinary pulmonary rehabilitation: a randomised controlled trial. Lancet 2000;355(9201):362-8. http://dx.doi.org/10.1016/\$0140-6736(99)07042-7

36. Izquierdo JL, Barcina C, Jimenez J, Munoz M, Leal M. Study of the burden on patients with chronic obstructive pulmonary disease. Int J Clin Pract 2009;63(1):8797. http://dx.doi.org/10.1111/j.1742-1241.2008.01936.x

37. World Health Organization. International Classification of Functioneing, Disability and Health. Geneva: World Health Organization, 2001.

38. Celli BR, Cote CG, Marin JM, et al. The body-mass index, airflow obstruction, dyspnea, and exercise capacity index in chronic obstructive pulmonary disease. $N$ Engl J Med 2004;350(10):1005-12. http://dx.doi.org/10.1056/NEJMoa021322

39. Piredda M. Patient education: a concept analysis. Int Nursing Perspect 2004; $4(2): 63-71$

40. Stamler LL. Toward a framework for patient education. An analysis of enablement. J Holist Nurs 1996;14(4):332-47. http://dx.doi.org/10.1177/089801019601400406 